\title{
De que hoje padecem os professores da Educação Básica? ${ }^{1}$
}

\section{Do Basic Education teachers suffer from what today?}

\author{
Marcelo Ricardo Pereira ${ }^{2}$
}

\begin{abstract}
RESUMO
O artigo constrói um espectro possível que entremeia os territórios da educação e da saúde no que tange ao mal-estar docente de hoje. Trata-se de algo muito alardeado, mas nunca profunda ou suficientemente esclarecido sobre o padecimento psíquico de professores que se dizem cada vez mais deprimidos, estressados, esgotados, angustiados, hipermedicalizados, em pânico ou desistentes. Com base na psicanálise, mas sem hermetismos conceituais, o texto desce aos detalhes e revela as forças desse mal-estar: a inibição do professor de se colocar à prova, sua coragem moral invertida e o recuo de seu desejo. Passa-se a compreender não apenas o que docentes narraram sobre suas vidas e práticas, mas também o quanto o aspecto genealógico, o narcisismo e a ausência de saberes podem estar contribuindo para manter uma "zona de depressão moral", em que certos profissionais produzem o pior para si mesmos. E o que fazer? Através da "pesquisa-intervenção de orientação clínica", metodologia empregada para o trabalho, mostramos aos formadores e aos gestores educacionais dispositivos possíveis para que a palavra seja liberada, o sintoma seja destravado e a responsabilidade de cada um seja politizada.
\end{abstract}

Palavras-chave: mal-estar docente; padecimento psíquico; educação básica; psicanálise.

\footnotetext{
ABSTRACT

This article proposes to construct a possible spectrum that ties the territories of health and education as it regards the malaise that takes over teachers

DOI: $10.1590 / 0104-4060.49815$

$1 \mathrm{O}$ artigo decorre de projeto de pesquisa financiado pela Fundação de Amparo à Pesquisa do Estado de Minas Gerais e pelo Conselho Nacional de Desenvolvimento Científico e Tecnológico.

2 Universidade Federal de Minas Gerais. Belo Horizonte, Minas Gerais, Brasil. Av. Antônio Carlos, nº627. CEP: 31270-90.E-mail: marcelorip@hotmail.com
} 
nowadays. It supposes that this psychic suffering in teachers is not being deep or sufficiently clarified, considering that it is well-known. Teachers report they are increasingly depressed, stressed, exhausted, distressed, overmedicated, suffering of panic and producing dropouts. Based on the theoretical frame of psychoanalysis, but with no conceptual Hermeticism, this essay tries to enter into details and reveals the forces of this malaise: the inhibition that occurs in teachers' concerning of testing themselves, their reversed moral courage and the retreat of their desire. After this study, it becomes possible to understand not only what teachers narrate about their lives and practices, but also how the genealogical and narcissistic aspects, as well as the lack of knowledge, are contributing to keep a "moral depression zone", from where some of these professionals produce the worst for themselves. Therefore, what to do? Through the "intervention research of clinical guidance", the methodology employed in this research, we intend to give educational trainers and managers some devices to make it possible for teachers to speak. Releasing their words, they could unlock their symptoms and politicize their inner responsibility.

Keywords: teaching malaise; psychic suffering; basic education; psychoanalysis.

\section{Introdução}

No cotidiano de professores da educação básica, sobretudo de escolas públicas, tem sido comum eles se queixarem das mais diversas formas clínicas de sintoma como depressão (a mais recorrente), estresse, transtorno bipolar, fenômenos de pânico, problemas alimentares, obsessões, compulsões ou algum tipo de dependência química. Queixam-se ainda de certa paralisia profissional e também das síndromes de burnout e da "desistência", mal compensadas com o uso contínuo de psicofármacos, com as licenças médicas e mesmo com os desvios de função.

A destituição visível da autoridade de professores, o desinteresse discente generalizado, os confrontos e a banalização da agressividade e da violência intraescolar parecem atingir de chofre a saúde mental docente. Conforme narrado por vários, tal fenômeno ganhou a sala de aula e, concomitantemente às precárias condições de trabalho e à reduzida prática coletiva com colegas e gestores, isso vem se tornando o grande dilema que enfrentam para exercer o magistério. Uma angústia generalizada parece se apossar e estar asfixiando certo grupo de professores, provocando-lhes os mais diversos sintomas; uma angústia 
que, para além da dor de existir, designa hoje sie Hilflosigkeit (um desamparo), uma "zona de depressão moral" (LEGUIL, 2012, p. 127), que nos leva a perguntar: de que, afinal, padecem, não todos, mas certo grupo de professores da educação básica que pode estar apresentando modos bem específicos e atuais de sofrimento psíquico?

Como se pode notar, trazemos aqui um problema muito alardeado, bastante inflacionado, mas nunca profunda ou suficientemente esclarecido sobre o padecimento mental de professores da educação básica. Trata-se dos achados de uma pesquisa-intervenção de orientação clínica que propiciou espaços de fala para mais de 50 docentes do $6^{\mathrm{a}}$ ano do Ensino Fundamental ao $3^{\mathrm{o}}$ ano do Ensino Médio, de escolas públicas, que se dispuseram a estar conosco para narrarem suas vidas, experiências e formas de subjetivação.

Sem buscar nem culpados, nem heróis, procuramos compreender não apenas tais formas, mas também o quanto a escola pode estar corroborando para manter em baixa a coragem moral daqueles que porventura produzem para si mesmos algum tipo de morbidade psíquica. Porém, como diz Freud (1916-17/1980, p. 289), "não se deseja com isso suscitar conviç̧ão; se deseja estimular o pensamento e derrubar preconceitos".

\section{Questões de Método}

A pesquisa-intervenção que realizamos pautou-se numa metodologia própria para o trabalho, baseada no que denominamos "atitude" ou "orientação clínica". Intervimos no sentido de levar o professor a refletir sobre sua prática, a compreender fenômenos, a destravar identificações, a pensar intervenções e a elaborar-se subjetivamente. Baseando-se no princípio técnico e seminal da psicanálise que Freud (1914/1980) denominou "recordar, repetir, elaborar", demos à pesquisa um direcionamento clínico sem ser propriamente terapêutico, mas, antes, voltado para uma análise estritamente social, reflexiva e elaborativa do real. Seguimos assim a tradição do pensamento de vários autores que aplicam a escuta clínica no campo social, ou seja, intervimos "nos lugares onde os sintomas contemporâneos são recolhidos. Isso não quer dizer que eles sejam entendidos ou tratados, mas sim que deixam traços em alguns lugares". (LAURENT, 2007, p. 177).

Cabe dizer que a pesquisa-intervenção de orientação clínica insere-se mais além da pesquisa-ação e da pesquisa participante ao trabalhar as singularidades discursivas (e não tanto as regularidades). Em uma perspectiva diferente dos 
cientistas sociais, buscamos menos as grandes categorias sociais e mais as formas singulares e microfísica do ser falante. Com efeito, enquanto sociólogos, historiadores e outros pensadores centram-se na reconstituição e compreensão regular dos acontecimentos e dos discursos, um trabalho de orientação psicanalítica - sem desprezar esse princípio - centra-se mais nos modos singulares de como um acontecimento é sorrateiramente repetido ao ser narrado, e não apenas recordado ou contado. Importam menos os fatos, as consciências ou as cronologias, e mais a repetição singular que as falas e os silêncios dão a conhecer no que tentam igualmente ocultar.

É de se notar que os estudos que empregam a pesquisa-intervenção têm crescido muito no campo da educação, da saúde e do direito e revelam-se como um modo diferente e alternativo de investigação, já que propõe pesquisas com sujeitos e não sobre eles. Apesar de muito empregada na psicologia social e de não ser um modelo investigativo exclusivo da psicanálise, a pesquisa-intervenção tem nesse último campo de saber uma sustentação bastante fértil. Justamente por sua longa tradição clínica na escuta das formas de subjetivação ao fazer falar aquele que sofre, a psicanálise auxilia substancialmente esse tipo de pesquisa propondo, ao mesmo tempo, que se investigue algo, e também que se libere a palavra, ao fazê-la circular em francos espaços de fala. Busca-se com isso "levar o sujeito a produzir o que não se espera: uma novidade, um novo significante, uma fala plena. Algo que o surpreenda e que o subjetive". (PEREIRA, 2016, p. 74).

Entendemos que a clínica não se reduz somente às práticas de consultórios de médicos, psicólogos e psicanalistas. Mas a tomamos como uma atitude ou uma conduta que permite pôr em marcha um sujeito em constante reflexão para que se tenha também a chance de fazer sua subjetividade realizar-se. Consideramos a clínica como um lugar privilegiado de acontecimento do sujeito, de fazê-lo vir à superfície e inscrever-se como efeito de uma atitude. Nesse sentido, concordamos com André Green (2004, p. 11) quando escreve que "existe em psicanálise não somente uma teoria da clínica, mas um pensamento clínico, isto é, um modo original e específico de racionalidade extraído da experiência prática”.

Mireille Cifali (2001) é precisa quando recupera a proposição de Jacques Ardoino ao dizer ser clínico aquilo que deseja apreender o sujeito através de um sistema de relações em cujo prático se reconheça efetivamente envolvido com a transformação daquele que sofre. Para isso, buscamos estratégias de intervenção que se nivelam à "clínica das urgências subjetivas" (PEREIRA, 2016, p. 78), que podem ser assim traduzidas: (1) localizar a posição subjetiva de quem fala a partir de sua escuta, destacando modos fixos de gozo ou de satisfação pulsional; (2) estabelecer rapidamente as possíveis hipóteses - já que não se tem o tempo da clínica convencional; (3) propiciar a transferência ao longo de todo o processo; (4) suspender as resistências e os semblantes; (5) 
recortar o caráter repetitivo do sintoma; e (6) intervir pontualmente, sobretudo, por meio de "citação" , com fins de ajudar o sujeito a fazer seu sintoma vacilar. Fazê-lo vacilar é auxiliar o sujeito a formalizar esse sintoma e a mover-se de tal formalização, de modo a propiciar o destrave de identificações para se alcançar algum modo de elaboração subjetiva.

Nem todos a alcançam - poucos, talvez -, mas consideramos que, entre aqueles que a alcançam, haverá uma oportunidade maior de entender um pouco mais a si: suas incoerências, ambivalências, despolitizações, repetições, seus truques de manipulação institucional, seu "ódio sádico, mascarado pela idealização do aluno". (MANNONI, 1973, p. 37).

Nossa tarefa é então fazer vacilar o sintoma de quem o porta, levando-o a pôr sob suspeita a certeza que identifica o sujeito à sua condição sintomática. Assim, por exemplo, aquele que diz "eu sou deprimido" nomeia a si mesmo com seu próprio sintoma, se condenando a uma inércia sem fim. Ele se iguala a alguma predeterminação nosográfica, substancializando-se nela a ponto de elevá-la à condição de nome próprio. Uma coisa é dizer "eu sou deprimido"; a outra é "eu estou deprimido (e posso não estar)". Procuramos, com nossas intervenções, induzir sujeitos a fazer heuristicamente esse nome dessubstancializar-se e deslocar-se. Isso reconhece o caráter contingente do sintoma e pode levar os sujeitos a alterarem identificações fixas, fazendo-os buscar outras soluções para o que os faz padecer. Desse modo, desumanizamos a nosografia para humanizar quem acredita portar algo dela.

Apesar dos limites temporais e do alcance de tal orientação clínica, uma vez não estando em uma psicanálise convencional, nem sendo seu intento, a empregamos no viés de uma psicanálise aplicada ao sintoma; e não no viés de uma psicanálise aplicada à fantasia (como tradicionalmente se espera da clínica standard). O sintoma foi o nosso foco.

Quanto à "caixa de ferramentas" (FOUCAULT, 1979), lançamos mão de pesquisa documental a partir de fontes de órgãos de governo (secretarias municipais e estaduais de educação e da saúde situados na cidade de Belo Horizonte). Escolhemos uma amostragem de escolas e docentes com base em tais fontes, mas também empregamos o contato direto a partir da ferramenta "bola de neve" (DEWES, 2009), através da qual alguns sujeitos sabem reconhecer e indicar uns aos outros porque, em parte, conhecem atitudes ou comportamentos

3 Lacan divisa duas formas de interpretação em análise que denominou "enigma" e "citação". Consideramos que a primeira requer o tempo da espera que, muitas vezes, não se tem numa clínica das urgências subjetivas. Mas a "citação" pode ser melhor empregada, pois em regra ela se apoia no enunciado do falante (autor), devolvendo-lhe o seu próprio significante (ver LACAN, 1969-70/1992, p. 35 e segs.). 
comuns que os tornam próximos. Em cada escola, criamos "espaços de fala" (BESSET; COUTINHO; COHEN, 2008, p. 92), com 1 a 5 encontros grupais de até 10 sujeitos, totalizando um coletivo de mais de 50 professores. Procedemos também a "observação de singularidades" (PEREIRA, 2016; BARROS; LEHFELD, 1986), voltada mais às situações contingentes e microfísicas. Dos 50 docentes, escolhemos 15 para realizar "entrevistas de orientação clínica" (PEREIRA, 2016), que são entrevistas de profundidade com caráter de formalização do sintoma com fins de intervenção. Também se fez uso de "diário de bordo" (BARROS; LEHFELD, 1986) e de "diário clínico" (FERENCZI, 1932/1993) para o registro tanto de informações, experiências e impressões, numa atitude de poder refletir sobre a prática, quanto da pessoalidade do próprio pesquisador, de si mesmo, numa atitude de refletir-se na prática.

\section{Resultados: "fuga para a doença"}

Considerando a escuta dos professores com os quais estivemos, será muito difícil concluir que os problemas que enfrentam sejam causados propriamente por seus alunos. Essa suspeita inicial mostrou-se muito pouco evidente. A relação com o aluno, sobretudo o adolescente, pode até contribuir para disparar alguma morbidade psíquica, mas, ao contrário do anunciado por esses mesmos professores no começo dos espaços de fala, imputando a esses alunos a causa de suas desordens, o que se revelou nas narrativas seguintes foi algo de outra natureza. Foi algo, talvez, que diga respeito muito mais à "covardia moral", ao "recuo do desejo" ou à "fuga para a doença". Essas são expressões freudianas que parecem reatualizadas de certa forma na "miséria neurótica" que, no geral, esses professores apresentam com seus dramas microfísicos.

Sabemos desde Freud (1916-17/1980, p. 529) que um sujeito, nas condições em que se acham os professores escutados, parece ser incapaz de "aproveitar a vida e realizar-se". É incapaz de aproveitá-la porque seu investimento não se dirige a nenhum objeto real, mas a uma sucessão de objetos imaginários ("objetos irreais da libido"), de produção subjetivamente empobrecida, que lhe roubam grande quantidade de valiosa energia ao empregá-la no sentido de manter seus assaltos sob controle. Seus sintomas parecem propiciar algo que, mesmo subtraindo-lhes a possibilidade de aproveitar a vida, os faz gozar um pouco dela. Eis o caráter bifásico do sintoma (de problema e solução). Por um lado, ele representa um ato de "covardia moral", em que se cede de seu desejo em nome de certo apagamento ou demissão subjetiva; e, por outro, uma medida 
defensiva que se acha à disposição do Eu; medida essa que não viria a favor do desejo, mas contra ele. Em todo caso, como assinala Freud (1893/1980, p. 170), "uma dose maior de coragem moral teria sido vantajosa para a pessoa em causa".

Em se tratando de cada professor que escutamos, essa covardia moral e essa defesa do Eu parecem ter um nome próprio: o "estado depressivo". Situamos esse estado muito mais no campo da "miséria neurótica" do que no campo da melancolia, que tributaria ao Eu uma deserção absoluta e precoce por parte do outro, a ponto de condená-lo a modalidades fronteiriças dos delírios psicóticos. Diferentemente da melancolia, o estado depressivo seria na verdade uma expressão de defesa contra o horror ante o vazio da existência ou contra o horror por não se achar em condições de atender às demandas do outro social. Longe da angústia de despedaçamento, próprio das psicoses, e muito mais próximo da angústia da castração neurótica, o estado depressivo parece revelar algo ainda mais peculiar: uma espécie de aflição petrificada que se passa quando a pessoa que sofre imagina como asfixiante o outro que sustenta o seu narcisismo. Ora ele é aquele que opressivamente o invade, ora ele é aquele que desamparadamente lhe falta.

Não temos dúvidas de que a depressão - ao lado de fenômenos associados como a ansiedade, o desespero, a irritabilidade e o pânico - protagoniza o quadro sintomático da grande maioria dos docentes que estiveram conosco. Eles o confirmam através de diagnóstico médico, do autodiagnóstico ou da influência discursiva de como esse quadro vem se alastrando e se banalizando em nossos tempos. Não se pode dizer, porém, que todos os docentes que se disseram depressivos realmente sejam. A força de generalização desse diagnóstico parece imperar entre eles. Apuramos sua incidência em mais de $60 \%$ daqueles que participaram dos espaços de fala, e, entre aqueles que foram entrevistados, pudemos auscultar a pertinência do estado depressivo em doze dos quinze professores ouvidos.

$\mathrm{Na}$ verdade, parece prevalecer uma certa nebulosa diagnóstica ou um certo espectro do estado depressivo que se deriva de modos fronteiriços e não bem definidos da estrutura e do sintoma psíquico. Em nossos dias, concorrendo com as formas clínicas já conhecidas, passamos a contar com a surpreendente intensificação das novas formas de padecimento psíquico, como as disposições depressivas e melancólicas; as angústias difusas; os fenômenos de pânico e borderlines; as desordens da oralidade e da adicção (a exemplo da bulimia, anorexia, compulsão alimentar, toxicomania e alcoolismo). Essas novas formas têm se tornado um desafio à comunidade psicanalítica no sentido de manejar seus próprios limites técnicos e de criar novos dispositivos clínicos que sejam capazes de acolher os modos de subjetivação e padecimento de nossa época. 
No caso dos professores, é notável a presença dessa nebulosa oscilatória e pouco estável da angústia ou da "produção de uma nova sintomatologia, de origem mais inespecífica, queixas e sentimentos mais vagos, comumente referindo-se a uma mistura entre tédio e desencanto". (SANTOS; SANT'ANNA, 2009, p. 133).

Para eles, o estado depressivo viria a funcionar como um refúgio contra a urgência das demandas do outro; demandas essas exteriores, ocupacionais e relacionais (CORDIÉ, 1998), advindas de agentes como projetos governamentais, cumprimentos de programa e a lida difícil com alunos indóceis. O problema é que o docente que supostamente apresenta um quadro depressivo, como a maioria daqueles que estiveram conosco, consegue muito pouco desviar-se do imperativo superegoico de satisfazer o outro com suas demandas. "Quanto mais ele se esconde, mais fica à mercê dele". (KEHL, 2009, p. 21).

Assombra perceber que vivemos numa sociedade do direito ao gozo ou à satisfação pulsional imediata, que por isso deveria ser uma sociedade antidepressiva, com a promoção de ideais ligados ao prazer, à alegria, à fruição. Mas um mundo mais hedonista gera um mundo mais angustiado devido ao caráter insuportável do prazer não regulado. Temos hoje uma cultura menos recalcada do que foi a de Freud. Isso não quer dizer que sejamos mais livres, pois não somos. Se os interditos foram relativamente postos em suspensão, fizemos do excesso não algo a se recalcar, mas um direito. Estamos numa civilização da maximização do gozo e, quanto mais se acede a ele, mais esse gozo se mostra inalcançável, e mais o sujeito se achará em dívida com o Supereu.

Nossa hipótese para o estado depressivo no professor relaciona-se a uma posição que ele ocupa de se demitir subjetivamente para escapar dessa dívida. Porém, ele não consegue. $\mathrm{O}$ professor acaba se deprimindo justamente por rechaçar esse empuxo ao gozo que a civilização fomenta e, em consequência, sofrer a culpa fundamentalmente superegoica que a psicanálise lacaniana traduz como "ceder de seu desejo". (LACAN, 1959-60/1988, p. 385).

Suspeitamos de que o professor que venha a ceder de seu desejo é aquele que se deixa cair antes da queda. Essa é a hipótese de Mauro Dias (2004), também relembrada por Kehl (2009), que pode mostrar o quanto o sujeito nesse estado se inibe antes de se pôr à prova. Há uma covardia moral nessa operação de cair antes da queda e a inibição é seu corolário: "temos aqui um ponto a partir do qual deve ser possível chegar a uma compreensão da condição da inibição geral que caracteriza estados depressivos". (FREUD, 1926/1980, v. 20, p. 110).

Uma inibição do ponto de vista da psicanálise é a expressão da restrição de uma função do Eu, uma defesa contra a angústia. Freud (1926/1980) considera que a inibição no trabalho leva o sujeito ou a viver uma diminuição do seu prazer nele, ou a tornar-se menos capaz de realizá-lo bem, ou ainda a 
experimentar certas reações no tocante à própria atividade laboral, como esgotamento, estresse, irritabilidade, etc. É bem o que acontece com os professores ouvidos. Resultam disso prostrações, conversões orgânicas, alimentares, além de uma tendência à distração, à dissimulação e à perda de tempo com delongas narcísicas. Aproveita-se pouco a vida desse modo, pois muitos tendem a revelar certa paixão pela ruína ao se aterem ao real a ponto de saberem antecipadamente que o pior sempre vence. Não é de se estranhar que atitudes de pessimismo, de autovitimização, de autopunição, com claros sentimentos de impotência e inferioridade, levem esses sujeitos a se inibirem frente ao pior e a se satisfazerem exatamente pelo fato de não se colocarem à prova.

Mesmo se sentindo permanentemente convocados a agirem, os docentes revelam o quanto as identificações com os pares, isto é, com as imagens daqueles que os circulam, mostram-se insuficientes para pautar a sua ação. Ninguém parece digno de ser identificado. Logo, com essa fragilidade identificatória, tais sujeitos não se sentem impelidos à ação. No caso do professor, agir em nome de quê? Por qual motivo? Para esses alunos pobres que nada querem saber? Para essa escola e educação falidas? Para essa sociedade doente? Mover em nome de qual desejo?

A maioria dos professores não nos esconde o quanto se demite subjetivamente. Não há outro que os motive a reagir. Isso parece se intensificar quando se trabalha com pessoas para as quais se tem pouquíssima ou nenhuma expectativa. Esses professores revelam uma explícita menos-valia atribuída aos alunos. Em geral, são pobres, moradores de favelas, vilas ou bairros periféricos, atendidos por uma escola que não os oferece nem perspectiva, nem futuro. Em reflexo, os docentes demonstram fazer o mesmo: julgam suas "famílias desestruturadas", com sérios problemas sociais, que levam seus filhos a terem uma frágil noção de limite e de interdito. Associam facilmente muitos jovens ao mundo ilícito das drogas e da contravenção, como o faz o senso comum. Uma vez nostálgicos, tendem a lamentar a inexistência da figura paterna na vida deles para assegurar-lhes algum vetor da lei. Todo esse quadro nos conduziu a três inferências formais que passamos agora a registrar e a analisar:

(1) Do ponto de vista genealógico, há que se interrogar: como estar em uma profissão sem cumprir a sua função de modificar o outro para poder governá-lo? Como exercê-la sem acreditar que o outro possa ser transformado a ponto de fazer parte de outra ordem social para a qual são educados? Os professores com quem estivemos demonstraram saber, de saída, ainda que não claramente, que são incapazes de cumprir os desígnios genealógicos de sua função; que são incapazes de servir de mola propulsora para catapultar seus "pobres" alunos a outra ordem diferente das originais. "Tive a sensação de que eu não vou conseguir mudá-los", disse uma professora. "É. Parece que você está ali 
enxugando gelo; você não muda a vida de ninguém, parece que a gente passou em branco", disse outra.

Se não podem mudá-los de fato, que se tenha pelo menos a ilusão de poder fazê-lo. Mas não é o que acontece. Logo, não se deve estranhar que professores, sem qualquer ilusão de modificação daqueles que guiam, não escolham outra coisa senão o ato de "jogar a toalha!" - declaração emblemática dita por vários professores e que traduz bem o que aqui evocamos como "ceder do desejo". O estado depressivo, em muitas vezes, pode ser o efeito disso. O sujeito evade-se e inibe-se a fim de evitar se deparar com a angústia de não ser capaz de fazer valer a sua função.

Mas, afinal, aonde quer chegar o professor que se demite subjetivamente? Desçamos mais aos detalhes, pois está em jogo aqui uma posição de recuo em relação à sua própria potência. Os professores que escutamos demonstram, em sua maioria, retirar-se do jogo e o denunciar antes de serem desmascarados: "eu posso não ser muito bom, então se eu reclamar muito do outro ai talvez justifique um pouco a minha falha", disse um deles.

Amiúde, demonstram narcisicamente rechaçar qualquer iniciativa de apropriarem-se de sua potência, de sustentá-la, de externá-la e, como tal, de colocá-la à prova, com todos os riscos que disso deriva. Logo, os desafios do cotidiano, como o desinteresse dos alunos, as afrontas juvenis, as fragilidades da organização escolar; bem como os dramas particulares, os desencontros conjugais, os lutos procrastinados e os secretos crimes privados, são capazes de promover uma inibição generalizada a ponto de paralisá-los com um amargo sentimento de impotência e de "despossessão de si". (BIRMAN, 2014, p. 117). Eis o que nos leva à nossa segunda inferência formal:

(2) Há uma presença excessiva do narcisismo que se pode observar no recuo da própria potência e, ao mesmo tempo, na não aceitação de sua condição de mortais, de finitos, de castrados. Ora, ser professor é admitir uma alta cota de narcisismo; um narcisismo profissional que parece impregnar a memória arcaica de todo aquele que se ocupa da docência, dizendo-lhe que estar nesse lugar é se nivelar de modo abnegado e nostálgico aos "grandes homens modernos": os mestres "autênticos", "emancipadores" e "simbólicos". (PEREIRA, 2008, p. 125). Entretanto, parece haver um abismo considerável entre ser um professor proletarizado do real de hoje e buscar ser um professor grandiloquente do imaginário de ontem - personagem que parece nunca ter existido, senão como fantasma "de uma hipotética ancestralidade perdida". O fato é que a profissão é bastante narcísica, de memórias e ilusões gloriosas e de pleno investimento em si. Mas é também uma profissão de muita rivalidade, muita afronta, com demasiado risco de deposição e de escárnio. Aceitar essa "profissão de risco" 
é aceitar um forte componente de incerteza e de conflito que podem ofender esforços de mascaramentos narcísicos.

Ora, todo narcisismo traz em si uma aura de infantilismo, isto é, uma satisfação aderente à maneira infantil, que, como sintoma, mescla restrição e satisfação. O sentimento de impotência é só a maneira final de algo que se inicia nesse pathos pela "doença", ou seja, nessa "forma infantil [e narcísica] de satisfação". (FREUD, 1916-17/1980, p. 427). Aliás, apresentar-se de saída como impotente, como ocorreu com a grande maioria dos professores escutados, não deixa de revelar-nos uma pretensão de onipotência secreta que eles preservam ao não se colocarem em risco diante de seus desafios pedagógicos cotidianos ou mesmo diante das atribulações de suas vidas particulares. Tendem a apegar-se, lúcida e orgulhosamente, às suas desgraças a ponto de confirmar seus pessimismos em relação ao trabalho, aos alunos, aos pares, à vida. Desse modo, eles se privam ao máximo das demandas sociais, do confronto e de não se medirem com o outro.

Suspeitamos de que no temor do desmascaramento de suas onipotências secretas, infantis e narcísicas é que reside boa parte do motivo de caírem antes da queda. O estado depressivo é o sintoma "escolhido" como uma defesa inibitória antecipada, uma defesa contra a angústia. Porém, não se trataria aqui de uma angústia como afeto que não engana ou como um afeto típico da relação com o real inassimilável (LACAN, 1962-63/2005), mas de uma tristeza petrificada, ansiosa, imaginária e abatida que acomete o sujeito e lhe mostra seu empobrecimento advindo do malsucedido de sua escolha narcísica.

(3) Por último, registramos uma ausência tácita de saberes ao ampliarmos a lente e percebermos que, na fala dos professores, à exceção de um ou dois, todos demonstram ter conhecimentos muito primários do que seja o básico de sua experiência. Eles sabem muito pouco sobre a sociedade contemporânea, a educação moderna e pós-moderna, a política pública que os rege, a escola de nossos tempos e muito menos o que seja o sujeito discente de hoje, bem como as novas formas de subjetividade e de diversidade cultural. Por mais que se dizem submeter a infindáveis cursos de formação para tal, algo lhes parece impermeável, pois seus estudos não os levam a ultrapassar o repetido conteúdo que ministram com rotineiros recursos pedagógicos. Aqueles que ultrapassam essa fronteira tendem a reduzir suas incursões culturais a mantras, mapas astrais, leituras religiosas, orientalismos e notícias do dia. A exceção se limitou a duas docentes que leem clássicos para suas atividades extraclasses, ligadas à arte. Assim, não deixamos de entender e dar crédito à fala de uma delas ao polemizar: "acho que vão descobrir isso: quanto mais estudo mais livre, melhor trabalha!"

No que concerne à educação, os professores da pesquisa-intervenção, em geral, não parecem saber muita coisa além do senso comum, nem sobre o sujeito 
com o qual lidam, tampouco sobre a escola em que trabalham. É certo que o saber e a formação em si não são garantias de um trabalho cotidiano melhor, mas, sem eles, fica muito restrita a possibilidade de manejá-lo. "Conhecer é tomar posse. Pensar é trabalho de reflexão". (CHAUÍ, 1982, p. 60). Um docente deve ser capaz de subjetivar o saber e a formação a ponto de fazerem parte de sua própria pessoalidade e capacidade de reflexão. Mas, ao inquirir os pesquisados, notamos uma ausência tácita de saberes. Tal fato pode ser um problema agudo para uma profissão narcísica como a docência. Como realizá-la sem mostrar para o outro social, que tanto lhes demanda ação e uma imagem potente para exercê-la, que eles são ineptos em temas que se situam no epicentro fundacional de sua profissão? Como atender às demandas desse outro, sejam elas exteriores, ocupacionais ou relacionais, sem conhecimento de causa e, ao mesmo tempo, sem se colocarem na berlinda e se angustiarem?

Quiçá muitos professores tenham se tornado exímios astutos em estratégias capilares para camuflarem suas fragilidades conceituais, políticas, sociais, bem como para o manejo do real que tais fragilidades não os permitem fazer. Além de queixarem-se de forma uníssona do desinteresse generalizado dos alunos, de ser "nada" para eles, é comum delatarem com razão as precárias condições institucionais, a reduzida infraestrutura escolar e a organização problemática do trabalho docente. Eles estão certos sobre isso, mas nos perguntamos se essas queixas também os ajudariam a ocultar suas fragilidades e mantê-los detrás de rotinas standards e maçantes.

Por razões ainda desconhecidas por nós, os docentes ouvidos demonstram não admitir sequer tais fragilidades, e convertem para seus corpos os efeitos malsucedidos dessa escolha. Fixados a objetos imaginários, tentam a duras penas mascarar suas debilidades pessoais e conceituais, sua má formação e suas ações despolitizadas, "elegendo" para si o sintoma social de sua época: o estado depressivo. Nesse sentido, parece estratégico cair antes da queda: "cair atirando para todos os lados" - diria um deles. Deprime-se justamente antes de o outro social saber da falha de sua pretensa e secreta onipotência, de seu narcisismo sem fundamento, de evitar agir em conformidade com o seu desejo. O estado depressivo não seria assim apenas padecimento, mas gozo.

Se podemos dizer que sempre que um neurótico enfrenta um conflito ele empreende uma fuga para a doença [...]. Refugiando-se na neurose, o Eu obtém internamente um certo ganho proveniente da doença [...]. Então, a doença se converte em uma arma na batalha contra o dominador - arma que pode usar para sua defesa e da qual pode abusar para sua vingança. (FREUD, 1916-17/1980, p. 446, grifos do autor). 
A notável observação freudiana para as neuroses, com suas fugas, ganhos e armas, pode muito bem ser estendida para os estados depressivos dos professores ouvidos. Eles toleram esse estado que, afinal, não podem evitar. Refugiam-se na "doença". Daí, o Eu de cada um tira dela as vantagens possíveis; porém, sabe inconscientemente que fez um negócio escuso em relação a essa escolha malsucedida pelo padecimento. Paga-se caro demais por um alívio do conflito. Com seus depoimentos espontâneos e verdadeiros, os docentes exibem, contra isso, as maiores lamentações e queixas acerca de seus sofrimentos, demonstrando decisão de cooperarem e de se exporem a fim de se ter alguma chance de sair dessa condição mórbida. Mas é bem o inverso disso. Estabelece-se "uma espécie de modus vivendi" - diz Freud (1916-17/1980, p. 448) -, pois o "ganho proveniente da doença" já lhes subtraiu alguma coragem moral para fazê-lo, ao se ter cedido de seu desejo.

A diferença do neurótico comum, de que fala Freud, para o neurótico em estado depressivo, como aqui o expomos, reside no fato de que o primeiro, mediante o vazio de não afirmar seu desejo, preencherá seu mundo com coisas, atuações e dramas a fim de obter algum tipo de reconhecimento do outro, lutando intimamente contra o fracasso; ao passo que o segundo, fugindo da culpa (lê-se angústia) de não agir conforme seu desejo, inibir-se-á a ponto de não se colocar à prova, eximindo-se, inclusive, da necessidade de buscar esse reconhecimento. Sabe de antemão que isso não viria sem o excesso opressivo da presença do outro.

A medicalização dos professores em estado depressivo, através de múltiplos rótulos de psicofármacos cujos usos detectamos maciçamente em nossos pesquisados, pode acentuar a covardia moral de refugiar-se em relação ao conflito. Em vez de ajudarem o sujeito a enfrentá-lo, os antidepressivos, ansiolíticos, hipnóticos e estabilizadores de humor, prescritos a catorze dos quinze entrevistados, bem como a mais de dois terços dos que participaram dos espaços de fala, podem produzir não uma coragem de viver, mas um apaziguamento de si. Um apaziguamento que corresponderia a um apagamento da dimensão conflitiva, bem como a um empobrecimento da vida subjetiva e do laço social de cada um. Isso apenas mostra, como reconhece Kehl (2009), uma falência teórica da psiquiatria que já não conta com hipóteses etiológicas para a compreensão de padecimentos psíquicos.

A nosso ver, achamos que, ao se alinhar a bases neurocientíficas da medicina e se distanciar de bases mais etiológicas, psicodinâmicas e clínicas de fenômenos psicológicos (como se deu em seu passado recente), a psiquiatria corre o risco de ser reduzida à pragmática da neurologia. Uma vez não se situando mais na turva área na qual se mesclam o somático e o psíquico, e fundamentando-se tão somente na biomedicina, a psiquiatria contemporânea 
abandona sua associação histórica à psicanálise - senão sua dependência - e se entrega aos desígnios discursivos de estudos sobre a química e o funcionamento do sistema nervoso central. As descobertas psicofarmacológicas, sobretudo dos últimos decênios, aceleraram bastante esse processo. Mas se do ponto de vista biológico isso pode ter sido um avanço, do ponto de vista subjetivo pode ter se tornado um desastre. Medicam-se, agora e apressadamente, tristezas, humores e comportamentos sem se dar a chance mínima ao sujeito de ter o tempo suficiente para elaborá-los por meio de seus próprios dispositivos simbólicos e, assim, poder sair deles mais fortalecido. "Toda depressão traz dentro de si mesma o germe da recuperação" (WINNICOTT, 1983, p. 60), mas em um mundo em que se rechaça todo e qualquer nível de dor, tenta-se a todo custo sedar a angústia e também eliminar as excitações e as paixões que a causam. A menos que essa dor seja suficientemente desorganizadora do sujeito, a ponto de ameaçar sua inserção social, não vemos por que - e aqui reside nossa posição - não se promover alguma forma que o leve a ser clinicamente acolhido antes de classificado ou de ser devidamente escutado antes de medicado.

\section{Conclusão: o que fazer?}

Julgamos ser fundamental que formadores e gestores entendam que dificilmente conseguiremos avançar sem que algo específico da prática do professor seja recolocado no epicentro do debate. Repensar suas condições de trabalho, sua remuneração, suas relações com o saber e com a formação são essenciais, mas, sobremaneira, precisamos auxiliar o professor a recuperar sua coragem moral para atuar em situações de incerteza e descontinuidades. Também devemos ajudá-lo a dar respostas mais ou menos rápidas mediante tais situações, a lidar com a apatia do alunado sem se tornar igualmente apático e a entender o "mal-estar na civilização" no circuito pedagógico.

Tal circuito cuidou para que hoje tenhamos um sem número de políticas de formação e de trabalho docente voltadas para um educador genérico, abstrato e teórico. Apela-se, desse modo, à inflação de saberes que são amiúde sustentados ou bem pelas referências às obras clássicas e seus mestres ou bem por modismos de teorias passageiras, que de tempos em tempos entorpecem o universo educativo. Mas, em oposição a isso, parece estar havendo em nossos dias uma espécie de sobrelevação daquilo que o sujeito julga como mais genuíno e digno de ser narrado: sua experiência, seus impasses e seus próprios modos de subjetivação. 
Talvez seja necessário aos agentes formadores, aos gestores pedagógicos e aos sistemas educativos em geral proporem ações mais efetivas que venham a aproximar, sem nunca extinguir, a distância entre o que se busca - a política - e o que se faz - a experiência. Seria uma política (ou uma micropolítica) que passe a levar em conta também a escuta e a "fala plena" (LACAN, 1953/1998) daqueles que realizam cotidianamente $o$ ato de ensinar.

Sabemos que, para isso, "nosso trabalho sempre terá de desenvolver-se por caminhos diferentes dos comuns". (AICHHORN, 1925/2006, p. 114). A orientação clínica e a escuta de professores foram a única maneira possível divisada por nós para que se possa proceder tal política. Acreditamos que seja plausível aos formadores e aos gestores de professores que admitem a orientação psicanalítica instituírem fóruns ou espaços de fala individuais e coletivos nos quais os docentes possam expor livremente seus impasses, experiências e subjetividades; que tenham, com isso, a chance de destravar formas fixas de sintoma.

A "fala plena" alcançaria o estatuto fundante de outra política para o exercício docente capaz de admitir algo de um laço inédito de ordem clínica. $\mathrm{Na}$ verdade, seria uma micropolítica que estimularia gestos que façam vacilar o sintoma e propiciar desidentificações, dessubstancializações e deslocamentos subjetivos. Da mesma forma que conduzimos nossa pesquisa-intervenção, liberando a palavra para que ela possa surpreender e produzir efeitos inéditos de elaboração, pensamos ser vital que haja nas escolas um profissional, na pessoa do pedagogo, do coordenador dessa área ou do formador de professores, que opere inspirado na técnica freudiana "recordar, repetir e elaborar". Para isso, deverá ter sido ele escutado subjetivamente, ter interrogado seus próprios sintomas, consentir com o inconsciente e oferecer-se como suporte transferencial de suposto saber para os que lhe procuram. Esse profissional deverá ser aquele que promova uma escuta apurada e, igualmente, faça intervenções mínimas - nunca longas -, sempre um pouco atrás e sem moralismos, de modo a fazer a palavra circular em francos espaços de fala. Lembremos de que a clínica trabalha com a palavra, mas essa palavra é, sobretudo, a do sujeito, e não de quem o dirige.

Será vital, a nosso ver, que essa clínica opere pela via do sintoma, fazendo-o ser falado e elaborado, heuristicamente, de modo a permitir a inscrição do sujeito no laço social de forma menos destrutiva, sem tanto fugir para a doença e autorizando-se a ponto de saber-fazer algo próprio com sua inscrição sintomática. Eis um tipo de saber artesanal que se encontra à revelia de saberes universais. Reforçamos a premissa de que aqueles que acompanham os profissionais do campo da educação devem necessariamente dispor-se a escutar e a acolher os sintomas que surgem no interior desse campo. E estamos seguros de que, no que concerne à investigação, a pesquisa-intervenção de orientação clínica pode ser um operador formidável para fazer circular a palavra, inverter a inércia que o 
sintoma substancializa e permitir novos modos de subjetivação de professores. Quem sabe, assim, se possa esperar que eles venham a fazer laços menos mortíferos com o real e a reverter aquilo de que padecem hoje muitos professores da educação básica.

\section{REFERÊNCIAS}

AICHHORN, A. Juventud desamparada. Barcelona: Gedisa, 1925/2006.

BIRMAN, J. O sujeito na contemporaneidade. Rio de Janeiro: Civilização Brasileira, 2014.

CHAUÍ, M. O que é ser educador hoje? In: BRANDÃO, C. (Org.). O educador: vida e morte. Rio de Janeiro: Graal, 1982.

CORDIÉ, A. Malaise chez l'enseignant: l'éducation confrontée à la psychanalyse. Paris: Le Seuil, 1998.

BARROS, A.; LEHFELD, N. Fundamentos de metodologia. São Paulo: McGraw-Hill, 1986.

BESSET, V.; COUTINHO, L.; COHEN, R. Pesquisa-intervenção com adolescentes: contribuiç̧ões da psicanálise. In: CASTRO, L.; BESSET, V. (Orgs.). Pesquisa-intervenção na infância e juventude. Rio de Janeiro: Trarepa/FAPERJ, 2008.

CIFALI, M. Conduta clínica, formação e escrita: In: PERRENOUD, P. et al. Formando professores profissionais: quais estratégias? Quais competências? 2. ed. Porto Alegre: Artmed, 2001.

DEWES, J. O. Amostragem em bola de neve e respondent-driven Sampling. Tese (Mestrado) - Instituto de Matemática da UFRGS, UFRGS, Porto Alegre, 2009.

DIAS, M. Cadernos de seminário: neurose e depressão. Campinas: EPC, 2004.

FERENCZI, S. Diário clínico. Rio de Janeiro: Imago, 1932/1993.

FOUCAULT, M. Microfisica do poder. Rio de Janeiro: Graal, 1979.

FREUD, S. Casos clínicos: miss Lucy R. Edição Brasileira das Obras Completas. Rio de Janeiro: Imago, 1893/1980. v. 2.

FREUD, S. Recordar, repetir, elaborar. Edição Brasileira das Obras Completas. Rio de Janeiro: Imago, 1914/1980. v. 12.

FREUD, S. Conferências introdutórias sobre psicanálise. Edição Brasileira das Obras Completas. Rio de Janeiro: Imago, 1916-17/1980. v. 16. 
FREUD, S. Inibição, sintoma e ansiedade. Edição Brasileira das Obras Completas. Rio de Janeiro: Imago, 1926/1980. v. 20.

GREEN, A. La pensée clinique. Paris: Odile Jacob, 2004.

KEHL, M. R. O tempo e o cão - a atualidade das depressões. São Paulo: Boitempo, 2009.

LACAN, J. Função e campo da fala e da linguagem em psicanálise. In: LACAN, J. Escritos. Rio de Janeiro: Zahar, 1953/1998.

LACAN, J. O seminário: Livro 7. A ética da psicanálise. Rio de Janeiro: Zahar, 195960/1988.

LACAN, J. O seminário: Livro 10. A angústia. Rio de Janeiro: Zahar, 1962-63/2005.

LACAN, J. O seminário: Livro 17. O avesso da psicanálise. Rio de Janeiro: Zahar, 1969-70/1992. p. 35.

LAURENT, E. A sociedade do sintoma. Rio de Janeiro: Contra Capa, 2007.

LEGUIL, F. Souffrances au travail. Paris: AST, 2012.

MANNONI, M. Éducation impossible. Paris: Seuil, 1973.

PEREIRA, M. R. A impostura do mestre. Belo Horizonte: Fino Traço/Argvmentvm, 2008.

PEREIRA, M. R. O nome atual do mal-estar docente. Belo Horizonte: Fino Traço/Fapemig, 2016.

SANTOS, T. C.; SANT'ANNA, A. Psicanálise aplicada às organizações: sobre os efeitos subjetivos do discurso do capitalismo. In: SANTOS, T. C. (Org.). Inovações no ensino e pesquisa em psicanálise aplicada. Rio de Janeiro: 7 letras, 2009.

WINNICOTT, D. Tudo começa em casa. São Paulo: Martins Fontes, 1983.

Texto recebido em 17 de dezembro de 2016. Texto aprovado em 03 de janeiro de 2017. 
